\title{
Correlates of vulnerability among arthropod species threatened by invasive ants
}

\author{
Paul D. Krushelnycky • Rosemary G. Gillespie
}

Received: 29 March 2009/ Accepted: 15 February 2010/Published online: 27 February 2010

(C) The Author(s) 2010. This article is published with open access at Springerlink.com

\begin{abstract}
Invasive species are causing population declines and extinctions of native species worldwide. Correlates of species vulnerability, which help identify at-risk taxa, are not well developed for arthropods, particularly with respect to threats from invasive species. At five sites undergoing invasion by ants in the Hawaiian Islands, we assessed body size, population density, trophic role and provenance (introduced or endemic to the Hawaiian Islands) as potential correlates of vulnerability for 300 arthropod species. Among rare species, provenance was the most important factor associated with absence from invaded plots, with endemic species much more commonly absent. Trophic role was also important, but only when interacting with provenance: endemic carnivores were by far the most vulnerable group, followed by endemic detritivores. For non-rare species, Hawaii endemics were significantly more reduced in invaded plots compared to introduced species. In addition, species that occurred at lower population densities were more vulnerable than those occurring at higher densities. Body size did not correlate with vulnerability for either rare or non-rare species. Despite these trends, there was relatively high variability in responses to invasion among species in many taxonomic orders, as well as among populations of particular species at different sites. While the consideration of additional intrinsic traits might increase predictive ability to some degree (e.g., intrinsic traits only explained $21 \%$ of the variation in impact among non-rare species), community-specific extrinsic factors appear to play a large role in influencing outcomes for many species, making prediction substantially more difficult.
\end{abstract}

Keywords Vulnerability - Extinction - Invasive ants · Arthropods · Hawaii

Electronic supplementary material The online version of this article (doi:10.1007/s10531-010-9819-8) contains supplementary material, which is available to authorized users.

P. D. Krushelnycky · R. G. Gillespie

Department of Environmental Science, Policy and Management, University of California, 137 Mulford Hall, Berkeley, CA 94720-3114, USA

P. D. Krushelnycky $(\bowtie)$

Department of Plant and Environmental Protection Sciences, University of Hawaii, 3050 Maile Way, 310 Gilmore Hall, Honolulu, HI 96822, USA

e-mail:pauldk@hawaii.edu 


\section{Introduction}

Invasive species are estimated to be among the leading causes of global biodiversity loss (Wilcove et al. 1998). Biological invasions may cause population declines, and even extinctions, of native species through various direct and indirect pathways (Mack et al. 2000), and global climate change may magnify these impacts (Hellman et al. 2008). Because risk of extinction is usually not distributed randomly among species (McKinney 1997), it is important to understand which species tend to be most vulnerable and what factors promote this vulnerability.

Both ecological theory and the fossil record predict that certain traits will predispose species to higher risk of extinction (McKinney 1997). Based on this idea, numerous studies have sought to correlate vulnerability with biological and ecological traits for many different vertebrate groups (e.g., reviewed in McKinney 1997; Reynolds 2003; Fisher and Owens 2004). The risk factors most frequently reported for vertebrates include small population density or size, small geographic range, high degree of ecological specialization, slow growth rate, low fecundity and high trophic position. In addition, it has been proposed that a lack of evolutionary experience with a particular predator or competitor should promote vulnerability among newly exposed species (Diamond and Case 1986; Ricciardi et al. 1998; Kats and Ferrer 2003). The importance of other traits, such as body size, can be highly variable among taxa (Reynolds 2003). Moreover, risk factors can vary according to the type of threat, for instance habitat loss versus hunting or predation by introduced species (Owens and Bennett 2000; Isaac and Cowlishaw 2004).

A smaller number of studies have investigated correlates of vulnerability for invertebrates (Reynolds 2003), and have focused on butterflies and moths (e.g., Thomas and Morris 1995; Warren et al. 2001; Franzén and Johannesson 2007), carabid beetles (Kotze and O'Hara 2003), hoverflies (Sullivan et al. 2000) and arthropod predators and herbivores on nettle plants (Zabel and Tscharnke 1998). The results from these studies, as with those on vertebrates, are not always consistent, but suggest that body size, degree of specialization, distributional range and mobility may be associated with vulnerability. The generality of risk traits across terrestrial arthropod groups, and whether they typically differ from those of other animals, remains unclear. In addition, nearly all of the aforementioned arthropod studies examine risk status, extinction, or population decline principally as a result of habitat loss or fragmentation. It is unknown whether the same traits will correlate with vulnerability when arthropods are threatened primarily by invasive species.

Invasive ants exert some of the most damaging impacts on arthropod communities (Holway et al. 2002) and hence are among the most thoroughly studied of insect invaders. Despite a fairly large number of case studies, it has been difficult to identify non-ant taxa that are consistently vulnerable to invasive ants (Human and Gordon 1997; Holway et al. 2002), and therefore to develop an understanding of what factors may promote vulnerability. This shortcoming could be due to real variation in vulnerability among sites, or alternatively may result from low taxonomic resolution masking real trends, or could be an artifact of methodological differences between studies. In the present study, we avoided these uncertainties by employing standard methods to examine the vulnerability of arthropods to invasive Argentine ants (Linepithema humile) and big-headed ants (Pheidole megacephala) at five sites in the Hawaiian Islands. The Hawaiian Islands are believed to have no native ant species (Wilson 1996), and the anthropogenic introduction of ants to the archipelago has long been considered to be devastating for the endemic arthropod fauna (Perkins 1913; Zimmerman 1970; Reimer 1994). We assessed whether body size, population density, or trophic role was correlated with vulnerability among a large number and 
wide variety of arthropod species. In addition, we examined taxonomic trends and the influence of provenance - the extent to which vulnerability can be attributed to a species being endemic rather than introduced to the islands. Finally, we used the high taxonomic resolution in this study to examine population-level variation in impact between communities. This allowed us to evaluate the importance of external context-dependent factors that might vary between sites versus intrinsic factors more tightly associated with species vulnerability.

\section{Methods}

Study sites

Five middle to high elevation mesic shrubland or savannah ecosystem sites were chosen on the islands of Maui and Hawaii, such that each represented a homogeneous habitat undergoing invasion by an expanding unicolonial population of invasive ants. The five sites were all located in natural areas supporting mostly native vegetation; none represented an invasion from a habitat edge. Habitat homogeneity within each site was judged by consistency of vegetative community type and species composition, as well as by the lack of apparent changes in substrate type or levels of disturbance. There were differences between sites, however, in substrate age, annual rainfall and vegetative type and composition, and hence arthropod density and diversity. The five sites were: Puu O Ili, at $2360 \mathrm{~m}$ elevation on the west slope of Haleakala volcano, Haleakala National Park, Maui; Kalahaku, upslope from Puu O Ili at 2800 m elevation in Haleakala National Park; Ahumoa, at $1880 \mathrm{~m}$ on the southwestern slope of Mauna Kea, Hawaii Island; Pohakuloa, at $2060 \mathrm{~m}$ elevation on the south slope of Mauna Kea, Hawaii Island; Huluhulu site, at $2040 \mathrm{~m}$ elevation in the saddle between Mauna Kea and Mauna Loa, Hawaii Island. These sites are described more fully in Krushelnycky and Gillespie (2008).

The Ahumoa site is being invaded by the big-headed ant ( $P$. megacephala), while the other four sites are all being invaded by the Argentine ant (L. humile). These two species are among the most dominant invasive ants worldwide, and are primarily generalist predators and scavengers, but can also engage in extensive tending of honeydew-producing Hemiptera (Holway et al. 2002). We chose to examine correlates of species vulnerability at the five sites together, combining the effects of the two ant species, for several reasons. In addition to their similar generalist diets, the two ant species are similar in size, and at our sites the big-headed ant occurred at densities and exerted impacts that were intermediate to those of the Argentine ant (Supplementary Table 1). Furthermore, big-headed ants did not influence rates of variability in population-level impacts differently than did Argentine ants (see "Results"), and separate laboratory behavioral studies indicated that the two ant species exhibited similar aggression towards the same groups of herbivore species (Krushelnycky 2007).

Sampling design

As in most studies examining the impacts of invasive ants on arthropod communities, we assessed ant effects by comparing arthropod communities in invaded areas with adjacent uninvaded areas. Our sites were carefully selected so as to minimize confounding factors that might be associated with static ant distributional limits, habitat gradients, or with invasions from habitat edges. Paired data from before and after invasion collected at two of 
the five sites support the inference that arthropod community differences between invaded and uninvaded areas can be attributed to the ants (Krushelnycky and Gillespie 2009). Hereafter, our use of language such as population 'declines' or species 'responses' refers to inferred changes resulting from ant invasion, and is shorthand for differences in measured densities between invaded and uninvaded plots.

At each site, we installed eight 5 by $5 \mathrm{~m}$ sampling plots into randomly selected habitat patches that contained all of the dominant shrub or tree species at the site (defined as the two to four most common shrub or tree species, see below), at a distance of 100-175 m behind the ant population boundaries. The longer distances were used at sites where invasion rates were faster; based on observed rates of spread, invaded plots were estimated to have been invaded for at least 4 years at all sites. These eight invaded plots were then matched with eight uninvaded plots in randomly selected habitat patches located $120-175 \mathrm{~m}$ in front of the expanding ant population boundaries, and were placed such that percent covers of the dominant plant species in the uninvaded plots deviated from those in matched invaded plots by less than 15\%. Methods for installing plots are elaborated in Krushelnycky and Gillespie (2008).

To quantify arthropod densities in each plot we employed three standardized sampling techniques, chosen to target the majority of species likely to interact with ants in these habitat types. First, we placed three pitfall traps $(300 \mathrm{ml}$ plastic cups half-filled with a 50:50 propylene glycol:water solution), separated by at least $2 \mathrm{~m}$, in each plot, with one randomly chosen trap baited around the rim with blended fish and the other two unbaited. These traps were left open for 2 weeks. Second, in each plot we collected leaf litter from three different areas, mixed it together and removed 1 liter, and placed this in a Berlese funnel for $24 \mathrm{~h}$. Third, in each plot we beat each of the dominant shrub or small tree species at the site. These plant species were: Ahumoa-Dubautia linearis, Dodonea viscosa; Pohakuloa-Myoporum sandwicensis, Sophora chrysophylla, Chenopodium oahuensis; Huluhulu-Leptecophylla tameiameiae, Vaccinium reticulatum, Coprosma ernodiodes; Puu O Ili-Dubautia menziesii, L. tameiameiae, V. reticulatum, S. chrysophylla; Kalahaku-D. menziesii, S. tameiameiae. Each plant species received five beats, spread among multiple individual plants in the plot if possible, over a $1 \mathrm{~m}^{2}$ beating sheet. Sampling occurred from August to September, 2002 at Ahumoa and Pohakuloa; June, 2003 at Kalahaku; July, 2003 at Puu O Ili; and August, 2003 at Huluhulu.

\section{Dataset}

We sorted all vegetation beating samples collected, but due to time constraints only sorted samples from five of the eight matched pairs of plots at each site for the pitfall and litter sampling techniques. All arthropods were identified to either species or morphospecies, with the exception of Acari (mites), Pseudococcidae (mealybugs), parasitic Hymenoptera, and immature individuals of some taxa. Immatures could be matched to adults for many taxa, though could only be determined definitively to genus, family, or sometimes order for others. In most cases, for the purposes of density estimation, immatures within a known taxon were assigned to species according to the relative densities of adults within that taxon. For example, if three species of Nysius seed bugs (Hemiptera: Lygaeidae) occurred in a plot, numbers of immature Nysius in that plot were allocated to these three species according to the proportional representation of the adults in that plot. In cases where immatures could only be identified to order or to families with many species (e.g., some Lepidoptera, Coleoptera and Araneae), these individuals were excluded from analyses, as were the unidentified Acari, Pseudococcidae and parasitic Hymenoptera. 
A total of 300 species or morphospecies from the five sites were identified with the help of many taxonomic specialists, and could be assigned as either endemic or introduced to the Hawaiian Islands according to Nishida (2002), other literature and specialist knowledge (Supplementary Tables 2 and 3). Additional identified taxa of ambiguous provenance were excluded from the analyses. All taxa are referred to hereafter as species. Voucher specimens are deposited at the Bernice P. Bishop Museum, the Essig Museum of Entomology, the University of Hawaii Insect Museum and the Haleakala National Park Insect Collection. Some species occurred at more than one site, resulting in 442 species $\times$ site incidences, which served as the total dataset for the analyses.

We assigned each species to one of three broad trophic roles (carnivore, herbivore, detritivore) based on reports in the literature. Very few species qualified as omnivores according to the definition of using both plant and prey resources (Coll and Guershon 2002), and these were excluded from regression analyses. The body size of each species was represented by its biomass, which we estimated from mean body length measurements of adults and immatures for each species using regression relationships of biomass on length (reported in Gruner 2003). The total number of individuals captured of each species in the uninvaded, reference area of each site ( $U$ in the terminology below) was used as an estimate of its relative population density.

\section{Impact of invasive ants}

We estimated the impact of invasive ants on arthropod species in two different ways, depending on whether the species was rare or not. We defined rare species as those that met the following two criteria: (1) the species occurred at a density of less than 5 individuals per total sampling effort in the combined uninvaded plots of a site, (2) this was true at each of the sites where the species was found. We pooled all samples among all invaded plots and among all uninvaded plots per site (combining captures from all three techniques) to produce estimates of population density in ant-invaded areas (I) and uninvaded areas (U) for each species at each site. We felt that this was appropriate, despite the possibility that different techniques might sample at different intensities and the fact that a different number of plots were sampled for ground versus arboreal techniques (5 plots versus 8 plots per area, respectively). Because there was no significant difference in the densities of non-rare species captured with each technique (one-way ANOVA, $F=1.34, P=0.265$, Supplementary Table 4), and there was no significant difference in the ratio of rare to non-rare species captured with arboreal versus ground techniques (Chi-square $=0.373, P=0.541$, Supplementary Table 5), there should be no substantial bias resulting from this pooling of samples.

For each non-rare species (128 species, Supplementary Table 2), an impact score was calculated as $(\mathrm{I}-\mathrm{U}) / \mathrm{U}$, at each site. This metric equals 0 when densities are the same in invaded and uninvaded plots (no impact), declines to a minimum of -1 , indicating the complete absence of a species in invaded plots, and is unbounded above 0 , suggesting positive impact (direct or indirect) due to ants. This metric is equivalent to Paine's index of interaction strength between a consumer and resource species (Paine 1992; Fagan and Hurd 1994), except that it does not adjust for per capita effect of the invading ant species. It is therefore a measure of the collective interaction strength of an invasive ant with other arthropod members of the community (Berlow et al. 1999).

Because this proportional measure of density change is sensitive to very low density values, we assessed vulnerability of rare species (172 species, Supplementary Table 3) to ant invasion by assigning a binary categorical response: absent in invaded plots, or present in invaded plots. The latter category included partial reductions in invaded plots, no 
difference between invaded and uninvaded plots, and higher densities in invaded plots. This dichotomy recognizes the greater tendency for sampling error at low species densities, and in comparison to simply differentiating between population decline and increase, is a more conservative measure of vulnerability to ant invasion.

\section{Analyses}

For the non-rare species dataset, we constructed a general linear model with impact score as the continuous response variable, and included the categorical explanatory variables provenance (endemic, introduced) and trophic role as well as the continuous explanatory variables body size and population density. Because the latter explanatory variable, population density (U), is also a component of the response variable, impact score (I-U)/U, this arrangement has the potential to produce a slight negative spurious relationship between impact score and population density simply by chance. However, low population density is usually thought to promote species vulnerability, which in this case would result in a positive relationship between population density and impact score. A finding of this predicted positive relationship, in spite of the statistical tendency towards a negative relationship, would therefore strongly indicate a real propensity for greater vulnerability among species that occur at low densities. We also included the variable ant density to control for potential effects caused by differences in ant density encountered by different species. Because our dataset included species scattered throughout the phylum Arthropoda, for which phylogenetic knowledge is very incomplete, it was not possible to generate phylogenetically independent contrasts (e.g., Owens and Bennett 2000; Sullivan et al. 2000; Fisher et al. 2003). Instead, we included taxonomic order as a variable in the regression model to control for major phylogenetic trends (Kotze and O'Hara 2003; Koh et al. 2004).

For species that occurred at multiple sites, we averaged the multiple impact scores for inclusion in the model; we therefore also averaged the species population densities and ant densities at the multiple sites where each species occurred. To meet assumptions of normality in linear regression, we log-transformed the explanatory variables population density and body size, and included the response variable as $\log ($ impact score +2 ). We started with a full model that included all of the main effects, plus all first order interactions between the four primary explanatory variables of interest. We simplified the model by backward elimination of the least significant variable, checking at each step that the model fit was not significantly diminished according to a partial $F$-test. We chose to keep the two variables that were not of primary interest (order and ant density) as main effects in the final model regardless of their significance since the purpose of their inclusion was to reveal the unique contributions of the other variables.

For the rare species dataset, we constructed a logistic regression model with presence/ absence in invaded plots as the binary categorical response variable, and included the categorical explanatory variables provenance and trophic role as well as the continuous explanatory variable body size. As in the non-rare species model, we included the variables ant density and order to control for these factors. For species that occurred at multiple sites, we scored a species as absent in invaded plots only if it was absent at all of the sites. We log-transformed the variable body size before inclusion in the model. We started with a full model that included all of the main effects, plus all first order interactions between the three primary explanatory variables of interest. We simplified the model through backward elimination of the least significant variable, checking at each step that the model fit was not significantly diminished according to the likelihood ratio test. All linear regressions were performed with Minitab v. 14 (Ryan et al. 2005). 
In a separate analysis, we examined the relationship between population density and likelihood of drastic population decline, among all species. We defined drastic population decline as possessing a sampled distribution in which at least $90 \%$ of individuals were captured in uninvaded plots (taking the average among sites for species that occurred at multiple sites). This level of inferred population reduction, while somewhat arbitrary, identifies those species that are arguably the most likely to experience local extinction. We grouped species, both rare and non-rare, by successively larger population density categories, such that evenness was maximized among all but the lowest density category (in terms of number of species included) for both endemic and introduced species. We then calculated the percentage of species exhibiting patterns of drastic population decline in each density category. Because the likelihood of obtaining a highly skewed sampling distribution purely by chance is much higher among small populations, we also calculated the percentage of species expected to exhibit patterns consistent with drastic population decline, through random sampling alone, for each population density category. We did this by (1) calculating the probability of obtaining $90 \%$ or more of sampled individuals in uninvaded plots for each observed population size, under the assumption that each individual had equal probability of existing in an invaded versus uninvaded plot, (2) multiplying these probabilities by the number of species that occurred at each population size, and (3) summing over population sizes and dividing by the total number of species, within each density category. Finally, we calculated a chance-corrected likelihood of drastic population decline for each density category by subtracting the percentage of species expected to exhibit patterns of drastic decline due solely to chance from the observed percentage of species exhibiting this pattern.

To examine variability in the inferred response to ant invasion, both within and among species, we tabulated species responses within each order, using the entire dataset including multiple incidences of species occurrence. Species were classified according to the identity and consistency of their responses. For non-rare species, we designated four categories: species whose responses were always strongly negative (impact scores $\leq-0.5$ at all sites), always weakly interacting (between -0.5 and 0.5 at all sites), always strongly positive ( $\geq 0.5$ at all sites), or variable (including scores in more than one of the categories at different sites). Rare species were classified into three categories: those that were absent in invaded plots at all sites, those that were present in invaded plots at all sites, and those that had variable responses among sites. For both rare and non-rare species, we also calculated a rate of population variability for each order, which was the percentage of species that were variable in their responses among the total number of species that could be variable (i.e., occurred at more than one site). Finally, we examined whether the bigheaded ant had a different effect on rates of population-level variability than did the Argentine ant. We tabulated all instances in which an arthropod species exhibited the same versus a different response (according to the categories above) between two populations invaded by Argentine ants, and compared this ratio using a Chi-square test to the same ratio for instances in which one population of a species was invaded by the Argentine ant and a second was invaded by the big-headed ant.

\section{Results}

Regression models

The final model assessing impact of ants on non-rare species suggests that the provenance of a species and its population density are the two most important correlates of 
Table 1 Vulnerability of non-rare species to ant invasion: general linear model predicting species impact scores $^{\mathrm{a}}$

\begin{tabular}{lrrrr}
\hline Variables in final model & df & Adj SS & $F$ & $P$ \\
\hline Order & 12 & 0.4310 & 0.97 & 0.484 \\
Ant density & 1 & 0.0933 & 2.51 & 0.116 \\
Population density & 1 & 0.2992 & 8.06 & 0.005 \\
Provenance & 1 & 0.3849 & 10.37 & 0.002 \\
\hline
\end{tabular}

${ }^{a}$ Final model $R^{2}=20.76 \%$

vulnerability, even after adjusting for ant density and taxonomic order (Table 1). Species endemic to the Hawaiian Islands had lower impact scores (indicating stronger negative impacts and/or weaker positive impacts) than introduced species, and impact scores increased with increasing population density (indicating weaker negative impacts, or stronger positive impacts, at higher population density). The heightened vulnerability of species occurring at lower densities was evident in spite of a potential statistical tendency towards the opposite relationship (see "Methods"). Body size and trophic role were not significantly associated with impact $(P=0.635$ and $P=0.540$, respectively, when added to final model). There was little phylogenetic trend in the overall dataset, with none of the mean impact scores for orders differing significantly from each other. Removal of the variable ant density had no qualitative effect on the model. Overall, the model explained about $21 \%$ of the variance in impact score.

For rare species, the logistic regression model suggests that, after controlling for ant density and order, the provenance of a species is important as a correlate of vulnerability, and that trophic role is also important but is conditionally dependent on provenance (Table 2). Rare introduced herbivores were least vulnerable to ants (only $21.2 \%$ of species were absent in invaded plots), while rare endemic carnivores were most vulnerable $(88.9 \%$ of species were absent in invaded plots). This variation in vulnerability can be expressed in terms of odds ratios (Table 2), which estimate the odds of a particular species group being absent in invaded plots relative to a reference group (in this case introduced herbivores). Among rare endemic species, it is clear that herbivores, and to a lesser extent detritivores, were less vulnerable to invasive ants than carnivores. In contrast, there appeared to be little if any difference in vulnerability between trophic groups of rare introduced species.

As with non-rare species, body size had no association with rare species vulnerability ( $P=0.906$ when added to final model). There was a small amount of phylogenetic signal with respect to vulnerability, with Hymenoptera (including both endemic and introduced species) being significantly more likely to be absent in invaded plots than the reference order, Araneae (Table 2). Ant density was again relatively unimportant, and its removal did not qualitatively change the model. A classification table using a predicted probability cut point of 0.5 indicated that the model correctly classified $73.5 \%$ of all species. However, only $42.4 \%$ of vulnerable species-those that were absent in invaded areas-were correctly classified.

Likelihood of drastic population decline

Endemic species that occurred at lower population densities were much more likely to exhibit patterns of drastic population decline compared to higher density species (Fig. 1). 
Table 2 Vulnerability of rare species to ant invasion: (A) logistic regression model predicting probability of being absent in ant-invaded plots ( $\log$ likelihood $=-88.10, G=41.90, P<0.001$ ); (B) odds ratios for species groups being absent in invaded plots relative to introduced herbivores, the least vulnerable group

\begin{tabular}{|c|c|c|c|c|}
\hline & Coef & SE & $z$ & $P$ \\
\hline \multicolumn{5}{|c|}{ (A) Variables in final model } \\
\hline Constant & -2.3472 & 1.2204 & -1.92 & 0.054 \\
\hline Order & $-^{\mathrm{a}}$ & $--^{\mathrm{a}}$ & $-^{\mathrm{a}}$ & $-{ }^{\mathrm{a}}$ \\
\hline Ant density & -0.0001 & 0.0001 & -0.90 & 0.367 \\
\hline \multicolumn{5}{|l|}{ Provenance $^{\mathrm{b}}$} \\
\hline Endemic & 3.6374 & 0.9218 & 3.95 & $<0.001$ \\
\hline \multicolumn{5}{|l|}{ Trophic role $^{c}$} \\
\hline Herbivore & -0.2243 & 0.6822 & -0.33 & 0.742 \\
\hline Detritivore & 0.2234 & 0.6528 & 0.34 & 0.732 \\
\hline \multicolumn{5}{|l|}{ Provenance $*$ trophic role } \\
\hline Endemic * herbivore & -2.9266 & 1.1143 & -2.63 & 0.009 \\
\hline Endemic * detritivore & -2.3009 & 1.1523 & -2.00 & 0.046 \\
\hline Group & Odds & & & \\
\hline
\end{tabular}

(B) Odds ratio of being absent in invaded plots, relative to introduced herbivores

$\begin{array}{lll}\text { Introduced detritivore } & 1.56 & 0.35,6.98 \\ \text { Introduced carnivore } & 1.25 & 0.33,4.77 \\ \text { Endemic herbivore } & 2.04 & 0.60,6.96 \\ \text { Endemic detritivore } & 5.96 & 0.99,35.85 \\ \text { Endemic carnivore } & 47.55 & 6.57,344.22\end{array}$

\footnotetext{
${ }^{a}$ Only one order, Hymenoptera, had a coefficient significantly different from the reference order, Araneae (coef. on Hymenoptera $=3.083 \pm 1.328, z=2.32, P=0.020$ )

${ }^{\mathrm{b}}$ Reference group $=$ introduced

${ }^{c}$ Reference group $=$ carnivore
}

When this observed likelihood was corrected for the probability of obtaining patterns consistent with drastic decline purely by chance, species that occurred at densities of five to eight total individuals appeared to be at greatest risk (Fig. 1). While it is impossible to know for certain whether the highest observed rate of drastic decline among the rarest species (one to four individuals) was due more to actual vulnerability rather than sampling bias, it seems unlikely that these rare species would be less vulnerable than slightly more common species (five to eight individuals). The chances of bias from sampling error virtually disappear at higher population sizes, making it clear that the likelihood of drastic decline decreased markedly and remained relatively constant above a population density threshold of about nine to 15 individuals. Fifty-seven to $65 \%$ of the endemic species sampled in these communities had population densities that fall below this threshold, placing them at high risk. For introduced species, the trend between population density category and probability of drastic decline was weaker. Introduced species that occurred at relatively low population densities appeared to be much less vulnerable than corresponding endemic species, but vulnerability was fairly similar for higher density introduced and endemic species. 

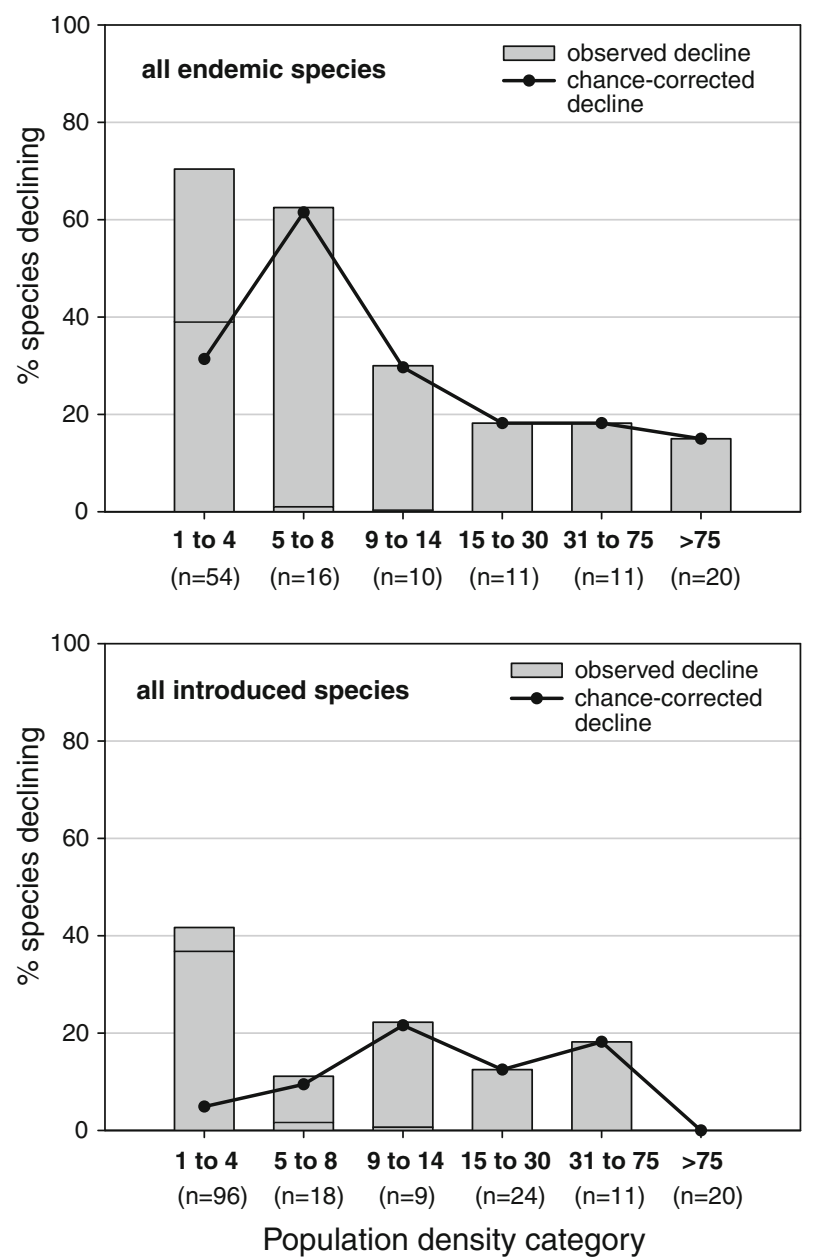

Fig. 1 Relationship between arthropod population density and likelihood of drastic population decline (defined as having at least $90 \%$ of all individuals captured in uninvaded plots). Species are grouped by density categories; numbers in parentheses indicate number of species in each category. Gray bars show the observed percentage of species exhibiting patterns of drastic decline. Horizontal lines within gray bars show the percentage of species expected to exhibit patterns of drastic decline purely by chance. Above population densities of about 9-14 individuals, this latter percentage essentially drops to zero. Black dots connected by lines show the chance-corrected likelihood of drastic decline for each category (calculated as the observed percentage minus the percentage expected by chance)

Taxonomic trends and variability

Several taxonomic orders in these arthropod communities stand out as being particularly vulnerable to invasive ants, when accounting for provenance. Endemic beetles (Coleoptera) and spiders (Araneae), both rare and non-rare species, were strongly reduced in invaded areas with high consistency (Tables 3, 4). In addition, endemic barklice (Psocoptera) and non-rare endemic moths (Lepidoptera) were more likely than not to be strongly reduced in invaded areas. Several additional orders had high rates of negative impact, but these were 
Table 3 Responses of non-rare species to ant invasion, grouped by taxonomic order ${ }^{\mathrm{a}}$

\begin{tabular}{llllll}
\hline Class & Order & \multicolumn{2}{l}{ Impact score $^{\mathrm{b}}$} & $\begin{array}{l}\text { Rate of pop } \\
\text { variability (\%) }\end{array}$ \\
\cline { 2 - 4 } & $\%$ negative & $\%$ weak & $\%$ positive & $\%$ variable & \\
\hline
\end{tabular}

(a) endemic species

$\begin{array}{lllllll}\text { Arachnida } & \text { Araneae } & 100(5) & 0(0) & 0(0) & 0(0) & 0 \\ \text { Diplopoda } & \text { Cambalida } & 100(1) & 0(0) & 0(0) & 0(0) & \text { na } \\ \text { Entognatha } & \text { Collembola } & 42.8(3) & 28.6(2) & 0(0) & 28.6(2) & 100 \\ \text { Insecta } & \text { Coleoptera } & 100(3) & 0(0) & 0(0) & 0(0) & \text { na } \\ \text { Insecta } & \text { Diptera } & 20.0(1) & 20.0(1) & 20.0(1) & 40.0(2) & 100 \\ \text { Insecta } & \text { Hemiptera } & 47.6(10) & 19.0(4) & 14.3(3) & 19.0(4) & 44.4 \\ \text { Insecta } & \text { Lepidoptera } & 85.7(6) & 14.3(1) & 0(0) & 0(0) & \text { na } \\ \text { Insecta } & \text { Psocoptera } & 60.0(6) & 10.0(1) & 20.0(2) & 10.0(1) & 50.0 \\ \text { Insecta } & \text { Thysanoptera } & 33.3(1) & 0(0) & 0(0) & 66.7(2) & 100 \\ \text { Overall } & & 58.1 & 14.5 & 9.7 & 17.7 & 65.7 \\ \text { (b) introduced } & \text { species } & & & & & \\ \text { Arachnida } & \text { Araneae } & 20.0(2) & 20.0(2) & 10.0(1) & 50.0(5) & 83.3 \\ \text { Chilopoda } & \text { Lithobiomorpha } & 0(0) & 0(0) & 0(0) & 100(2) & 100 \\ \text { Diplopoda } & \text { Julida } & 0(0) & 100(1) & 0(0) & 0(0) & 0 \\ \text { Entognatha } & \text { Collembola } & 25.0(3) & 16.7(2) & 8.3(1) & 50.0(6) & 100 \\ \text { Insecta } & \text { Coleoptera } & 40.0(2) & 20.0(1) & 40.0(2) & 0(0) & 0 \\ \text { Insecta } & \text { Diptera } & 33.3(2) & 0(0) & 16.7(1) & 50.0(3) & 100 \\ \text { Insecta } & \text { Hemiptera } & 33.3(5) & 26.7(4) & 26.7(4) & 13.3(2) & 40.0 \\ \text { Insecta } & \text { Neuroptera } & 0(0) & 100(1) & 0(0) & 0(0) & \text { na } \\ \text { Insecta } & \text { Psocoptera } & 28.6(2) & 0(0) & 0(0) & 71.4(5) & 83.3 \\ \text { Insecta } & \text { Thysanoptera } & 50.0(2) & 25.0(1) & 25.0(1) & 0(0) & \text { na } \\ \text { Malacostraca } & \text { Isopoda } & 50.0(1) & 0(0) & 0(0) & 50.0(1) & 100 \\ \text { Overall } & & 29.2 & 18.5 & 15.4 & 36.9 & 67.4\end{array}$

\footnotetext{
${ }^{a}$ For this summary, all species by site incidences were considered individually, i.e., responses for multipleincidence species were not averaged among sites

${ }^{\mathrm{b}}$ Species in each order were classified as having impact scores that were strongly negative at all sites (impact score $\leq-0.5$ ), weak at all sites $(-0.5<$ impact score $<0.5$ ), strongly positive at all sites (impact score $\geq 0.5$ ), or variable among sites (in more than one category). Number in parentheses is the number of species in each category

${ }^{c}$ Rate of population variability for each order was calculated as the number of species that had variable responses among sites divided by the number of species that occurred at more than one site, times 100 . "na" signifies that none of the species occurred at multiple sites
}

represented by single species, making it difficult to draw conclusions. Overall, at least one endemic species in each order was strongly impacted at one or more sites. Among introduced species, only Hymenoptera (bees, wasps and a pair of relatively uncommon ant species) were consistently impacted by ants. The remaining orders were much more variable among species in the inferred responses to ant invasion.

Variability was also high among populations of species: for both endemic and introduced taxa, roughly one-third to two-thirds of the species that occurred at more than one site responded to ants differently at different sites (Tables 3,4). This population-level 
Table 4 Responses of rare species to ant invasion, grouped by taxonomic order ${ }^{\mathrm{a}}$

\begin{tabular}{|c|c|c|c|c|c|}
\hline \multirow[t]{2}{*}{ Class } & \multirow[t]{2}{*}{ Order } & \multicolumn{3}{|c|}{ Presence in invaded plots ${ }^{b}$} & \multirow{2}{*}{$\begin{array}{l}\text { Rate of pop } \\
\text { variability }(\%)^{\mathrm{c}}\end{array}$} \\
\hline & & $\%$ absent & $\%$ present & $\%$ variable & \\
\hline
\end{tabular}

(a) endemic species

\begin{tabular}{|c|c|c|c|c|c|}
\hline Arachnida & Araneae & $66.7(2)$ & $33.3(1)$ & $0(0)$ & 0 \\
\hline Entognatha & Collembola & $100(1)$ & $0(0)$ & $0(0)$ & na \\
\hline Insecta & Coleoptera & $90.9(10)$ & $9.1(1)$ & $0(0)$ & na \\
\hline Insecta & Diptera & $36.4(4)$ & $54.5(6)$ & $9.1(1)$ & 50.0 \\
\hline Insecta & Hemiptera & $57.1(8)$ & $35.7(5)$ & 7.1(1) & 100 \\
\hline Insecta & Hymenoptera & $33.3(1)$ & $66.7(2)$ & $0(0)$ & na \\
\hline Insecta & Lepidoptera & $42.8(3)$ & $57.1(4)$ & $0(0)$ & na \\
\hline Insecta & Neuroptera & $100(1)$ & $0(0)$ & $0(0)$ & na \\
\hline Insecta & Psocoptera & $66.7(4)$ & $33.3(2)$ & $0(0)$ & na \\
\hline Insecta & Thysanoptera & $50.0(1)$ & $50.0(1)$ & $0(0)$ & 0 \\
\hline Overall & & 59.3 & 37.3 & 3.4 & 37.5 \\
\hline \multicolumn{6}{|c|}{ (b) introduced species } \\
\hline Arachnida & Araneae & 11.1(1) & $55.6(5)$ & $33.3(3)$ & 75.0 \\
\hline Diplopoda & Julida & $0(0)$ & $0(0)$ & $100(1)$ & 100 \\
\hline Entognatha & Collembola & $0(0)$ & $100(1)$ & $0(0)$ & na \\
\hline Insecta & Coleoptera & $16.7(6)$ & $69.4(25)$ & $13.9(5)$ & 38.5 \\
\hline Insecta & Dermaptera & $100(1)$ & $0(0)$ & $0(0)$ & 0 \\
\hline Insecta & Diptera & 46.7(7) & $26.7(4)$ & 26.7(4) & 100 \\
\hline Insecta & Hemiptera & $22.2(4)$ & 61.1(11) & $16.7(3)$ & 60.0 \\
\hline Insecta & Hymenoptera & $100(5)$ & $0(0)$ & $0(0)$ & 0 \\
\hline Insecta & Lepidoptera & $33.3(1)$ & $33.3(1)$ & $33.3(1)$ & 100 \\
\hline Insecta & Neuroptera & $0(0)$ & $0(0)$ & $100(2)$ & 100 \\
\hline Insecta & Orthoptera & $0(0)$ & $100(1)$ & $0(0)$ & na \\
\hline Insecta & Psocoptera & $0(0)$ & $83.3(5)$ & $16.7(1)$ & 50.0 \\
\hline Insecta & Thysanoptera & $14.3(2)$ & $57.1(8)$ & $28.6(4)$ & 57.1 \\
\hline Overall & & 24.1 & 54.5 & 21.4 & 61.9 \\
\hline
\end{tabular}

${ }^{a}$ For this summary, all species by site incidences were considered individually, i.e., responses for multipleincidence species were not averaged among sites

b Species in each order were classified as to whether they were absent from invaded plots at all sites, present in invaded plots at all sites, or exhibited different responses at different sites (variable). Number in parentheses is the number of species in each category

c Rate of population variability for each order was calculated as the number of species that had variable responses among sites divided by the number of species that occurred at more than one site, times 100 . "na" signifies that none of the species occurred at multiple sites

variability was not dependent on which species of ant was invading. Of 195 comparisons of paired population responses, pairs in which both populations (of the same arthropod species) were invaded by Argentine ants had a nearly identical ratio of same to different responses as did pairs of populations in which one was invaded by Argentine ants and the second was invaded by big-headed ants (Argentine-Argentine pairs exhibited the same response $49.1 \%$ of the time, Argentine-big-headed pairs exhibited the same response $46.8 \%$ of the time; Chi-square $=0.100, P=0.752$, Supplementary Table 6). 


\section{Discussion}

Oceanic island faunas are well known for their vulnerability to extinction. Island endemic species, for example, account for over $60 \%$ of documented animal extinctions worldwide (May et al. 1995). Many of these extinctions can be attributed at least in part to impacts resulting from introductions of wholly new faunal elements, such as terrestrial mammals (Simberloff 1995; Balmford 1996). Although arthropod extinctions and their causes are much more poorly documented, it has long been suggested that species endemic to remote oceanic archipelagos possessing few or no native social insects are similarly ill-equipped, due to their evolutionary isolation, to withstand the novel predatory and competitive pressures of invasive ants (e.g., Zimmerman 1970; Howarth 1985; Gillespie 1999). In the present study examining the impacts of invasive ants on arthropod species in five Hawaiian communities, provenance was strongly associated with vulnerability. Both rare and nonrare endemic species were more likely than introduced species to be less abundant or absent in invaded plots, even after adjusting for such traditionally important factors as population density, trophic role and body size, and additionally controlling for ant density and major phylogenetic effects. This result is largely in accordance with the impressions and findings of biologists going back nearly a century (Krushelnycky et al. 2005).

Although it seems likely that evolutionary naiveté has rendered Hawaiian arthropod species more vulnerable to invasive ants than their continental counterparts, the results of this study cannot definitively confirm that this is the case. This is because the introduced species in these Hawaiian communities do not represent any particular continental fauna, nor do they constitute a random sampling of continental species. Instead, they form a community of successful invaders, which could predispose them to be, on average, especially resilient to invasive ants. The same traits that are often thought to be correlated with invasion success, such as behavioral plasticity, high vagility and generalist diet (Lodge 1993; Fisher and Owens 2004), are likely to ameliorate the negative impacts of ants or any other dominant predators or competitors. A number of studies have examined the impacts of invasive ants on arthropods in continental ecosystems (e.g., Porter and Savignano 1990; Human and Gordon 1997; Holway 1998; Hoffmann et al. 1999; Bolger et al. 2000). While strong negative impacts on native ants are nearly universal in these studies, many also found evidence of negative impacts on numerous non-ant arthropod taxa. Results vary widely between communities, however, and differences in taxonomic resolution, usually combined with a failure to discriminate between native and non-native species, make it difficult to draw comparisons concerning inherent vulnerability between continental species and those endemic to Hawaii.

\section{Other correlates of vulnerability}

Aside from provenance, several other factors were associated with vulnerability to invasive ants. Population density was important for both endemic and introduced arthropods, with higher density species being less vulnerable than species occurring at lower densities. Moreover, for endemic species, there appeared to be a population density threshold below which species were at substantially higher risk (Fig. 1), with the majority of endemic species falling below this threshold. These results are consistent with studies in which low population density has been found to be strongly associated with extinction, threatened status, or likelihood of decline for many vertebrate groups, including Australian rainforest mammals (Laurance 1991), Mediterranean reptiles (Foufopoulos and Ives 1999), African birds (Newmark 1991) and primates and carnivores worldwide (Purvis et al. 2000). In 
contrast, two studies of butterflies failed to find a negative relationship between population density and either threatened status (Kotiaho et al. 2005) or likelihood of population reduction in habitat fragments (Shahabuddin and Ponte 2005). The difference in results between the latter studies and those presented here may stem from the difference in the types of threat involved. Butterfly species that exist at low densities are apparently able to tolerate habitat fragmentation and conversion in certain situations, whereas rare arthropod species may be unable to find refuges from a ubiquitous invading predator or competitor.

High trophic position has also been found to be correlated with increased vulnerability of extinction among vertebrates (McKinney 1997; Purvis et al. 2000), and top vertebrate predators typically disappear from all but the largest habitat fragments (Terborgh et al. 2001). Similarly, Zabel and Tscharnke (1998) found insect predators to be more sensitive to habitat patch isolation than insect herbivores. Among non-rare arthropod species in the present study, there was no evidence that carnivores were more vulnerable to invasive ants than were herbivores or detritivores. Among rare species, however, trophic role was significantly related to vulnerability, but only for endemic species. Rare endemic carnivores were by far the most likely group to be absent in ant-invaded plots (Table 2), with vulnerable species belonging to six different taxonomic orders. Rare endemic detritivores were the next most vulnerable group. One reason that carnivore species are often at risk is that they tend to exist at lower densities than herbivores and detritivores. But in these communities, trophic role was most clearly important for rare species, among which population density varied little. Instead, endemic carnivores at our study sites may be especially vulnerable to invasive ants because, in addition to experiencing direct predation and interference competition for feeding or refuge sites, they may also experience exploitation competition for prey resources. Invasive ants are also efficient scavengers, so they may similarly compete with some detritivores or omnivores for food resources (McNatty et al. 2009), although it has also been hypothesized that some detritivores may enjoy an increased resource base consisting of abundant ant carcasses in invaded areas (Porter and Savignano 1990; Cole et al. 1992). Herbivores, as a group, may be least vulnerable because most of them will not be competing with ants for food resources to any great extent. In addition, some endemic herbivores, such as delphacid planthoppers, are tolerated by ants, perhaps because they produce honeydew (Krushelnycky 2007, Supplementary Tables 2 and 3).

Finally, we found no association between body size and the likelihood or magnitude of population reduction as a result of ant invasion, regardless of whether a species was rare or not, or whether we controlled for other explanatory factors, including phylogenetic trends. Large body size is often correlated with other factors thought to increase vulnerability in animals, such as lower fecundity, slower development, lower abundance or density and larger range requirements (Reynolds 2003). These associations, however, do not always hold, leading to much variation among taxa in the relationship between size and vulnerability (McKinney 1997; Fisher and Owens 2004). In the present study, larger species had slightly lower densities and tended to occupy higher trophic positions than smaller species, which should make larger species less resilient to losses from ant predation. But at the same time, larger species may be preyed upon less frequently by relatively small invasive ants, and these two aspects of vulnerability may counteract each other. Although body size has been found to be positively correlated with increased vulnerability in several insect groups, including hoverflies (Sullivan et al. 2000), carabid beetles (Kotze and O'Hara 2003) and butterflies (Shahabuddin and Ponte 2005), our results are consistent with other studies on butterflies and moths that reported no relationship between body size and threatened status or risk of population extinction (Thomas and Morris 1995; Nieminen 1996; Koh et al. 2004; Kotiaho et al. 2005; Mattila et al. 2006). 
Variability, extrinsic factors, and the prediction of vulnerable endemic taxa

The goal of this analysis was to identify the life history traits of endemic species that correlate with the greatest risk of population declines or extinction. Our results indicate that among endemic Hawaiian arthropods, low population density and carnivory are risk factors, especially when co-occurring. Many additional species were negatively impacted by invading ants, however, indicating that the explanatory factors examined had relatively weak predictive power for a substantial subset of arthropods. Among non-rare species, for example, the best model only explained about $21 \%$ of the variation in average population response. For rare species, predictive power was better, but the best model still correctly classified only $42 \%$ of vulnerable species. Examination of trends among taxonomic orders was not overwhelmingly helpful. Endemic beetles and spiders showed the most consistency in their negative responses to ants (Tables 3, 4), as has been noted previously (Perkins 1913; Cole et al. 1992; Gillespie and Reimer 1993; Liebherr and Krushelnycky 2007). Spiders are all carnivores, but the beetles included three trophic classes, suggesting that endemic beetles share other traits that make them inherently vulnerable to invasive ants. Non-rare endemic moths were also consistently strongly impacted by ants (as in Cole et al. 1992), but this was not true of rare moths. For most of the remaining orders, a range of responses was observed and strong trends were not evident.

It is possible that the consideration of additional intrinsic factors could improve predictive ability, although many traits are not relevant, known, or easily measured across the wide range of orders considered here. For example, several studies have suggested that taxa possessing thick exoskeletons may be more resilient to invasive ants (Human and Gordon 1997; Hoffmann and Parr 2008). Similarly, Cole et al. (1992) made the point that two heavily sclerotized species, an introduced isopod and an endemic millipede, were found in higher abundance within ant-invaded areas at two of the same Hawaiian study sites used here. However, degree of sclerotization is difficult to quantify, and we did not find a consistent effect for this trait. In our study, the response of the isopod species in question (Porcellio scaber, reported as P. laevis in Cole et al. 1992) varied between sites, and among the three millipede species that we collected, two introduced species were slightly to much more abundant within invaded plots while an endemic species was nearly absent in invaded plots. Beetles are often heavily armored (at least as adults), yet were among the most vulnerable species, while some groups possessing relatively thin exoskeletons (e.g., some Hemiptera and Collembola) fared better. It may be that few traits will accurately predict vulnerability across such a wide phylogenetic range, and that analyses must examine more specific traits within narrower taxonomic groups to yield better results. These traits could be morphological, physiological or behavioral, and could include such factors as the production of honeydew or defensive compounds, or behaviors that shelter species from ant activity.

Although the examination of more specific intrinsic traits may be helpful, the high rates of variability shown in Tables 3 and 4 imply that there is a clear limit to the explanatory power of intrinsic traits. Species that had populations at multiple sites often exhibited strongly different patterns with respect to ant invasion among those sites, suggesting that extrinsic factors are responsible for the differences. One potential extrinsic factor, ant density, was not a significant explanatory factor for species vulnerability, at least within the range of densities observed here. Similarly, population-level variation in impact was not any greater when two sites were invaded by different ant species as compared to when they were both invaded by the same ant species, indicating that in this study system the identity of the invading ant was not an important factor. Instead, it seems likely that the specific 
community composition at each site determines to a large extent the outcomes of many species. For example, endemic detritivores and herbivores may experience direct mortality from ant predation, but may also experience release from other predators that decline when ants invade. As a result, the net effect will depend on the strength of predation by ants relative to that of the predators they replace, along with other direct and indirect food web interactions that may be influential (Krushelnycky 2007). Without a closer examination of such interactions, it may not be possible to produce accurate predictions for many endemic herbivore and detritivore species.

The high degree of variability in response to ant invasion in this system, among both species of the same order and populations of the same species, illustrates why previous attempts to identify higher taxa (e.g., families, orders) consistently vulnerable to invasive ants across studies and sites have encountered difficulties (Human and Gordon 1997; Holway et al. 2002). Studies of vertebrates have also often found limited predictive power from intrinsic traits alone (Blackburn and Gaston 2002; Fisher et al. 2003; Reynolds 2003), and it is clear that community composition and other extrinsic factors will complicate predictions in many other situations where species are threatened (Simberloff 1991; Williamson 1999). If it is not always possible to predict which species are at greatest risk, this uncertainty should only serve to underscore the importance of mitigating anthropogenic threats.

Acknowledgments We would like to thank the many specialists who identified or confirmed identifications of many of our specimens: K. Arakaki, M. Arnedo, J. Beatty, K. Christiansen, G. Edgecombe, N. Evenhuis, C. Ewing, A. Fjellberg, V. Framenau, J. Garb, W. Haines, S. Hann, J. Heinze, F. Howarth, B. Kumashiro, J. Liebherr, I. MacGowan, K. Magnacca, S. Marshall, W. Mathis, J. Miller, E. Mockford, S. Nakahara, D. Polhemus, D. Pollock, A. Pont, A. Ramsdale, G.A. Samuelson, B. Seifert, R. Shelley, C. Tauber, M. Tremblay, D. Tsuda, P. Vilkamaa, W. Weiner and M. Zapparoli. M. Anhalt, C. Berman, J. Long, M. Loope, A. Marks and K. Tice helped sort samples and made preliminary identifications. A. Taylor provided statistical advice, and B. Hoffmann, M. Power, G. Roderick and two reviewers made helpful comments on previous drafts. Funding came from the National Park Service Inventory and Monitoring Program, the National Science Foundation Graduate Research Fellowship Program, the Margaret C. Walker Fund, the Pacific Rim Research Program, and the Hawaii Audubon Society. Logistical support and access to collections was provided by the Department of Plant and Environmental Protection Sciences at the University of Hawaii, the Haleakala Field Station and Kilauea Field Station of the USGS's Pacific Island Ecosystems Research Center, Haleakala National Park, the Bernice P. Bishop Museum and the Hawaii Department of Agriculture. The Pacific Cooperative Studies Unit, Department of Botany, University of Hawaii, provided administrative assistance.

Open Access This article is distributed under the terms of the Creative Commons Attribution Noncommercial License which permits any noncommercial use, distribution, and reproduction in any medium, provided the original author(s) and source are credited.

\section{References}

Balmford A (1996) Extinction filters and current resilience: the significance of past selection pressures for conservation biology. Trends Ecol Evol 11:193-196

Berlow EL, Navarrete SA, Briggs CJ, Power ME, Menge BA (1999) Quantifying variation in the strengths of species interactions. Ecology 80:2206-2224

Blackburn TM, Gaston KJ (2002) Extrinsic factors and the population sizes of threatened birds. Ecol Lett 5:568-576

Bolger DT, Suarez AV, Crooks KR, Morrison SA, Case TJ (2000) Arthropods in urban habitat fragments in southern California: area, age, and edge effects. Ecol Appl 10:1230-1248

Cole FR, Medeiros AC, Loope LL, Zuehlke WW (1992) Effects of the Argentine ant on arthropod fauna of Hawaiian high-elevation shrubland. Ecology 73:1313-1322 
Coll M, Guershon M (2002) Omnivory in terrestrial arthropods: mixing plant and prey diets. Annu Rev Entomol 47:267-297

Diamond J, Case TJ (1986) Overview: introductions, extinctions, exterminations and invasions. In: Diamond J, Case TJ (eds) Community ecology. Harper and Row, New York, pp 65-79

Fagan WF, Hurd LE (1994) Hatch density variation of a generalist arthropod predator: population consequences and community impact. Ecology 75:2022-2032

Fisher DO, Owens IPF (2004) The comparative method in conservation biology. Trends Ecol Evol 19:391-398

Fisher DO, Blomberg SP, Owens IPF (2003) Extrinsic versus intrinsic factors in the decline and extinction of Australian marsupials. Proc R Soc Lond B 270:1801-1808

Foufopoulos J, Ives AR (1999) Reptile extinctions on land-bridge islands: life-history attributes and vulnerability to extinction. Am Nat 153:1-25

Franzén M, Johannesson M (2007) Predicting extinction risk of butterflies and moths (Macrolepidoptera) from distribution patterns and species characteristics. J Insect Conserv 11:367-390

Gillespie RG (1999) Naiveté and novel perturbations: conservation of native spiders on an oceanic island system. J Insect Conserv 3:263-272

Gillespie RG, Reimer NJ (1993) The effect of alien predatory ants (Hymenoptera: Formicidae) on Hawaiian endemic spiders (Araneae: Tetragnathidae). Pac Sci 47:21-33

Gruner DS (2003) Regressions of length and width to predict arthropod biomass in the Hawaiian Islands. Pac Sci 57:325-336

Hellman JJ, Byers JE, Bierwagen BG, Dukes JS (2008) Five potential consequences of climate change for invasive species. Conserv Biol 22:534-543

Hoffmann BD, Parr CL (2008) An invasion revisited: the African big-headed ant (Pheidole megacephala) in northern Australia. Biol Invasions 10:1171-1181

Hoffmann BD, Andersen AN, Hill GJE (1999) Impact of an introduced ant on native rain forest invertebrates: Pheidole megacephala in monsoonal Australia. Oecologia 120:595-604

Holway DA (1998) Effect of Argentine ant invasions on ground-dwelling arthropods in northern California riparian woodlands. Oecologia 116:252-258

Holway DA, Lach L, Suarez AV, Tsutsui ND, Case TJ (2002) The causes and consequences of ant invasions. Annu Rev Ecol Syst 33:181-233

Howarth FG (1985) Impacts of alien land arthropods and mollusks on native plants and animals in Hawaii. In: Stone CP, Scott JM (eds) Hawaii's terrestrial ecosystems: preservation and management. University of Hawaii Press, Honolulu, pp 149-179

Human KG, Gordon DM (1997) Effects of Argentine ants on invertebrate biodiversity in northern California. Conserv Biol 11:1242-1248

Isaac NJB, Cowlishaw G (2004) How species respond to multiple extinction threats. Proc R Soc Lond B 271:1135-1141

Kats LB, Ferrer RP (2003) Alien predators and amphibian declines: review of two decades of science and the transition to conservation. Divers Distrib 9:99-110

Koh LP, Sodhi NS, Brook BW (2004) Ecological correlates of extinction proneness in tropical butterflies. Conserv Biol 18:1571-1578

Kotiaho JS, Kaitala V, Komonen A, Päivinen J (2005) Predicting the risk of extinction from shared ecological characteristics. Proc Natl Acad Sci USA 102:1963-1967

Kotze DJ, O'Hara RB (2003) Species decline-but why? Explanations of carabid beetle (Coleoptera, Carabidae) declines in Europe. Oecologia 135:138-148

Krushelnycky PD (2007) The effects of invasive ants on arthropod species and communities in the Hawaiian Islands. Dissertation, University of California

Krushelnycky PD, Gillespie RG (2008) Compositional and functional stability of arthropod communities in the face of ant invasions. Ecol Appl 18:1547-1562

Krushelnycky PD, Gillespie RG (2009) Sampling across space and time to validate natural experiments: an example with ant invasions in Hawaii. Biol Invasions. doi:10.1007/s10530-009-9471-y

Krushelnycky PD, Loope LL, Reimer NJ (2005) The ecology, policy and management of ants in Hawaii. Proc Hawaiian Entomol Soc 37:1-25

Laurance WF (1991) Ecological correlates of extinction proneness in Australian tropical rain forest mammals. Conserv Biol 5:79-89

Liebherr JK, Krushelnycky PD (2007) Unfortunate encounters? Novel interactions of native Mecyclothorax, alien Trechus obtusus (Coleoptera: Carabidae), and Argentine ant (Linepithema humile, Hymenoptera: Formicidae) across a Hawaiian landscape. J Insect Conserv 11:61-73

Lodge DM (1993) Biological invasions: lessons for ecology. Trends Ecol Evol 8:133-137

Mack RN, Simberloff D, Lonsdale WM, Evans H, Clout M, Bazzaz FA (2000) Biotic invasions: causes, epidemiology, global consequences, and control. Ecol Appl 10:689-710 
Mattila N, Kaitala V, Komonen A, Kotiaho JS, Päivenen J (2006) Ecological determinants of distribution decline and risk of extinction in moths. Conserv Biol 20:1161-1168

May RM, Lawton JH, Stork NE (1995) Assessing extinction rates. In: Lawton JH, May RM (eds) Extinction rates. Oxford University Press, Oxford, pp 1-24

McKinney ML (1997) Extinction vulnerability and selectivity: combining ecological and paleontological views. Annu Rev Ecol Syst 28:495-516

McNatty A, Abbott KL, Lester PJ (2009) Invasive ants compete with and modify the trophic ecology of hermit crabs on tropical islands. Oecologia 160:187-194

Newmark WD (1991) Tropical forest fragmentation and the local extinction of understory birds in the eastern Usambara Mountains, Tanzania. Conserv Biol 5:67-78

Nieminen M (1996) Risk of population extinction in moths: effect of host plant characteristics. Oikos 76:475-484

Nishida GM (2002) Hawaiian terrestrial arthropod checklist, 4th edn. Bishop Museum Press, Honolulu

Owens IPF, Bennett PM (2000) Ecological basis of extinction risk in birds: habitat loss versus human persecution and introduced predators. Proc Natl Acad Sci USA 97:12144-12148

Paine RT (1992) Food-web analysis through field measurement of per capita interaction strength. Nature 355:73-75

Perkins RCL (1913) Introduction. In: Sharp D (ed) Fauna Hawaiiensis. Cambridge-at-the-University Press, Cambridge, pp xv-ccxxviii

Porter SD, Savignano DA (1990) Invasion of polygyne fire ants decimates native ants and disrupts arthropod community. Ecology 71:2095-2106

Purvis A, Gittleman JL, Cowlishaw G, Mace GM (2000) Predicting extinction risk in declining species. Proc R Soc Lond B 267:1947-1952

Reimer NJ (1994) Distribution and impact of alien ants in vulnerable Hawaiian ecosystems. In: Williams DF (ed) Exotic ants: biology, impact, and control of introduced species. Westview Press, Boulder, CO, pp 11-22

Reynolds JD (2003) Life histories and extinction risk. In: Blackburn TM, Gaston KJ (eds) Macroecology: concepts and consequences. Blackwell Publishing, London, pp 195-217

Ricciardi A, Neves RJ, Rasmussen JB (1998) Impending extinctions of North American freshwater mussels (Unionoida) following the zebra mussel (Dreissena polymorpha) invasion. J Anim Ecol 67:613-619

Ryan B, Joiner B, Cryer J (2005) Minitab handbook, 5th edn. Thomson Brooks/Cole, Belmont, CA

Shahabuddin G, Ponte CA (2005) Frugivorous butterfly species in tropical forest fragments: correlates of vulnerability to extinction. Biodivers Conserv 14:1137-1152

Simberloff D (1991) Keystone species and community effects of biological introductions. In: Ginzburg LR (ed) Assessing ecological risks of biotechnology. Butterworth-Heinemann, Boston, pp 1-19

Simberloff D (1995) Why do introduced species appear to devastate islands more than mainland areas? Pac Sci 49:87-97

Sullivan MS, Gilbert F, Rotheray G, Croasdale S, Jones M (2000) Comparative analyses of correlates of Red data book status: a case study using European hoverflies (Diptera: Syrphidae). Anim Conserv 3:91-95

Terborgh J, Lopez L, Nuñez V, Rao M, Shahabuddin G, Orihuela G, Riveros M, Ascanio R, Adler GH, Lambert TD, Balbas L (2001) Ecological meltdown in predator-free forest fragments. Science 294:1923-1926

Thomas JA, Morris MG (1995) Rates and patterns of extinction among British invertebrates. In: Lawton JH, May RM (eds) Extinction rates. Oxford University Press, Oxford, pp 111-130

Warren MS, Hill JK, Thomas JA, Asher J, Fox R, Huntley B, Roy DB, Telfer MG, Jeffcoate S, Harding P, Jeffcoate G, Willis SG, Greatorex-Davies JN, Moss D, Thomas CD (2001) Rapid responses of British butterflies to opposing forces of climate and habitat change. Nature 414:65-69

Wilcove DS, Rothstein D, Dubow J, Philips A, Losos E (1998) Quantifying threats to imperiled species in the United States. Bioscience 48:607-615

Williamson M (1999) Invasions. Ecography 22:5-12

Wilson EO (1996) Hawaii: a world without social insects. Bishop Museum Occasional Papers 45:3-7

Zabel J, Tscharnke T (1998) Does fragmentation of Urtica habitats affect phytophagous and predatory insects differently? Oecologia 116:419-425

Zimmerman EC (1970) Adaptive radiation in Hawaii with special reference to insects. Biotropica 2:32-38 